\title{
Valuing Environmental Public Goods: Deliberative Citizen Juries as a Non-Rational Persuasion Method
}

\author{
Solomon Geleta ${ }^{1}$, John Janmaat ${ }^{2}$, John Loomis ${ }^{3} \&$ Stephen Davies $^{4}$ \\ ${ }^{1}$ Department of Economics, School of Business and Economics, Thompson Rivers University, Kamloops, \\ Canada \\ ${ }^{2}$ Department of Economics, Philosophy and Political Science, University of British Columbia, Okanagan \\ Campus, Canada \\ ${ }^{3}$ Agricultural and Resource Economics, Colorado State University, Fort Collins, USA \\ ${ }^{4}$ IFPRI, Pakistan Agricultural Capacity Enhancement Program, Islamabad, Pakistan \\ Correspondence: Solomon Geleta, School of Business and Economics, Thompson Rivers University, Kamloops, \\ 905 University Drive, Kamloops, British Columbia, Canada V2C 0C8. Tel: (778) 586-4846. E-mail: \\ sgeleta@tru.ca
}

Received: February 22, 2018

Accepted: March 28, $2018 \quad$ Online Published: May 30, 2018

doi:10.5539/jsd.v11n3p135

URL: https://doi.org/10.5539/jsd.v11n3p135

\begin{abstract}
Governments sometimes use committees of selected volunteers to provide comment on environmental policy choices. We use a repeated choice experiment to explore how a deliberative citizen jury (DCJ) treatment affects the conservation preferences of DCJ participants who engage in a budget allocation exercise. First round choice experiment participants were invited to volunteer for one of a pair of paid DCJ sessions. Stated preference results for the DCJ participants were compared with a pseudo-control formed by matching non-participants on socioeconomic characteristics. Both preference and response heterogeneity declines for the DCJ treatment group, relative to the control. The stated preference results for the DCJ group are significantly different from those for the total sample, and the DCJ budget allocation results are inconsistent with the preferences expressed by the total sample. DCJ style committees may reflect how educated citizens make choices. However, selection and impacts of the deliberation make it likely these committees are not representative of the broader population.
\end{abstract}

Keywords: deliberative citizen jury, preference heterogeneity, response heterogeneity, propensity score matching, random parameter model

\section{Introduction}

Interest in determining the monetary values of goods and services provided by the environment has been growing. Some see such values as providing a more convincing way to argue for environmental protection. However, not everyone agrees with this notion of putting a value on the environment. Some say that we do not relate to the environment the way that we relate to a market basket of goods. The environment affects the whole community, so when we think about the importance of the environment, we may also think about the whole community, and, hence, money is not a "common denominator" that weighs heavily when individuals make choices that have environmental impacts. Therefore, there are disagreements on whether these monetary values reflect private values rather than the community or social value.

Over the past years, there have been efforts to measure the value that a sample of residents places on some of these environmental goods and services using stated preference environmental valuation techniques. Stated preference environmental valuation techniques assume that the equilibrium prices in a competitive market represent social values. However, many environmental goods and services do not have prices that meet this assumption (Dietz, Stern, \& Dan, 2009).

One of the recently adopted methodological processes to tackle this issue is that of deliberative citizen juries (DCJ), or the use of citizen groups convened to assess the costs and benefits of proposed management options. Although such methods are relatively new to the field of environmental valuation, participatory techniques have played a role in areas such as multicriteria decision analysis and risk assessment (Howarth \& Wilson, 2006; Vargas, Lo, Rohde, \& Howes, 2016). The process is believed to enhance citizen participation and improve the 
effectiveness, perceived quality, and legitimacy of policy decisions and monetary values. Moreover, DCJ overcome some of the critiques directed towards stated preference approaches, such as the concern that individuals may not have preformed preferences for environmental goods (Payne, Bettman, Schkade, Schwarz, \& Gregory, 1999); the notion of community rather than individual values (Sagoff, 1988); the problem of developing a detailed concept description of a resource improvement (Adamowicz, Louviere, \& Williams, 1994); reliance on the accuracy of the information and the completeness of any particular description of the good or service; time constraints (Cummings, Brookshire, \& Schulze, 1986; Dixon, Scura, Carpenter, \& Sherman, 2013; Mitchell, 2002); the protocols to be followed for carrying out surveys and other relevant considerations (Adamowicz et al., 1994; Ward, 1999); individuals' values towards matters of public policy and their sensitivity to changes in issue framing (Ward, 1999); the sensitivity of respondents' estimated values to the survey question context and perceived social importance (Schkade \& Payne, 1994; Schuman, 1996); and the opportunity for respondents to ask questions, discuss questions among themselves, and obtain information from a variety of sources (Ward, 1999). Specifically, respondents to choice experiment surveys may face the following challenges. They may have no predetermined preferences over different levels of the environmental goods (Álvarez-Farizo \& Hanley, 2006); they may believe that citizen rather than individual preferences are more relevant in social decision making ( ${ }^{\prime}$ lvarez-Farizo \& Hanley, 2006); they may have problems with the presentation of the scenario, the goods valued, and the attributes and levels taken by these attributes (cognitive burden on respondents) (Blamey, Gordon, \& Chapman, 1999; Morrison \& Kingsford, 2010); and they may have problems with the payment vehicle and the transaction method (Adamowicz et al., 1994; Farber, Costanza, \& Wilson, 2002; Ward, 1999).

Many of these critics argue that deliberation should be part of the valuation procedure. As an approach rooted in the principles of discursive democracy and social psychology, it may be charged with carrying out a variety of tasks that stated preference valuation methods lack, including the generation of narrative evaluations of proposed policy alternatives (Howarth \& Wilson, 2006). Sagoff (1998), for instance, introduced the idea of "citizen preferences" and argues that society decides on issues like the environment based on community preferences (rather than on individual preferences) even when it may disadvantage individuals in that society. Such preferences are not captured by traditional valuation techniques (i.e., contingent rankings, contingent choices, and choice experiments) (Aldred \& Jacobs, 2000; A' lvarez-Farizo \& Hanley, 2006; Macmillan, Philip, Hanley, \& Alvarez-Farizo, 2002). The presence of lexicographic preferences and protest votes in many valuation studies (Spash \& Hanley, 1995) offer support for a deliberative process that allows for the expression of values that cannot be measured using traditional methods (Aldred \& Jacobs, 2000; Álvarez-Farizo \& Hanley, 2006; Macmillan et al., 2002; Sagoff, 1998). Howarth and Wilson (2006) claims that "people can both understand the complex issues at stake and carefully consider their preferences and values through reasoned deliberation with others in their community and more informed decision can be achieved. Through such deliberation, new information may be revealed that was not shared beforehand by everyone in the group." Álvarez-Farizo, Gil, and Howard (2009) consider whether citizen preferences reflect the community objectives, implying that the citizens are responsible members of society, or personal objectives, implying that the citizens act as self-interested individuals during a traditional valuation exercise for non-market goods. Gregory (2000) claims that "a well-designed deliberative group procedure can increase the likelihood that policy decisions will meet with broad based approval and be viewed by taxpayers and elected officials as a sensible way to spend scarce funds." Gregory (2000) adds that citizen participation should be involved in framing decisions, defining key objectives, and establishing alternatives.

More recently, deliberation techniques have been extended to stated preference surveys ( $\mathrm{A}^{\prime}$ lvarez-Farizo \& Hanley, 2006; Powe, Garrod, \& McMahon, 2005). Usually, representative juries are selected using techniques such as random sampling (Howarth \& Wilson, 2006). Then, deliberation is added to a valuation study by using focus groups in both the design and interpretation stages (Kenter, Hyde, Christie, \& Fazey, 2011). For instance, Ahlheim et al. (2010) uses focus groups formed from a sample of respondents in the initial valuation study as "citizen experts" to aid in the design of a second round. Ferreyra and Beard (2007) let the focus groups define success and relate these definitions to group composition. They find a relationship between group structure and types of successes. Kontogianni, Skourtos, Langford, Bateman, and Georgiou (2001) uses stakeholder focus groups to identify key attitudes and opinions and to inform possible scenarios for wetland management on a Greek island. These scenarios are then used in a contingent ranking experiment. They argue that this mixed methodology informs policy options and relative trade-offs better than either method alone can. Gregory and Wellman (2001) use insights from stakeholder interviews and expert consultations to develop a workbook that is used by small groups of stakeholders to rank policy options. Among other things, they argue that inherent ecological uncertainty renders more sophisticated valuation estimates unreliable. MacMillan, Hanley, and Lienhoop (2006) examine the impact of different levels of information, time to think, and deliberation on valuation responses for 
a familiar (expanding wind power) and an unfamiliar (species introduction) environmental good. Treatments improve value estimates for the unfamiliar good but do not significantly impact estimates for the familiar good. $\mathrm{A}^{\prime}$ lvarez-Farizo and Hanley (2006) conduct a choice experiment with individuals and in a group setting to assess options for managing a Spanish river basin. They find that moving from an individual to a workshop valuation significantly changes the value estimates. Dietz et al. (2009) compares individual responses to an open-ended valuation survey on climate change policy with a carefully structured group deliberation designed to limit the amount of dominance or group think. Their finding shows that "deliberation leads people to consider different issues- thinking like a policymaker rather than a consumer- but willingness-to-pay values are unchanged." Lienhoop and MacMillan (2007) use psychological measures of engagement to compare the behavior of deliberation participants with that of individually interviewed participants in a contingent valuation study related to a hydro development in Iceland. Group participants are far more engaged with the material, and they suggest this increased engagement improves the quality of the valuation estimates. Although these studies also suggest that individuals have difficulty suspending their self-interest (Niemeyer \& Spash, 2001), participatory processes most likely overcome this problem and are seen as a legitimate mechanism for policy development (Howarth \& Wilson, 2006).

In this study, we borrow from these qualitative methodologies (Brown, Peterson, \& Tonn, 1995; Jefferson, 2016; Street, Duszynski, Krawczyk, \& Braunack-Mayer, 2014) and the market stall approach (Macmillan et al., 2002) to aid the survey design and examine the problem of basing policy on "uninformed" individual preferences. We do so by extending the conventional choice experiment approach and allowing individuals to deliberate in a citizen jury setting and undertake a choice decision for hypothetical environmental conservation policies. We estimate the deliberation treatment effect on choice outcomes by removing any significant differences in socioeconomic characteristics between the individuals who participated in the citizen jury (treatment sample) and those who completed the survey twice but did not volunteer (control sample). We specifically examine the congruity and the validity of the results from the DCJ method and from the choice experiment survey. We believe that integrating deliberative methods within the choice experiment process enhances our understanding of how respondents discuss and conceptualize the goods valued, respondents' thought processes during the transaction, the motivations for the respondents' responses, the adequacy of the valuation process used, and the public acceptability of the valuation exercise.

The next sections are structured as follows. In section 2, we outline the theoretical grounding of group deliberation and social decision-making. Section 3 discusses the citizen jury experiment procedures, characteristics, the sample, and the econometric estimation methods. In section 4, we provide choice data sorted and analyzed using the propensity score matching method and the environmental conservation option operationalized as a dependent variable, described by attribute levels, and in terms of deliberative and citizen jury processes. In addition, unobserved heterogeneities are captured by estimating a random parameter (RP) model, and willingness-to-pay (WTP) values are estimated and compared with the group DCJ value outcomes. The final section offers a conclusion, a brief discussion, and policy implications.

\section{Theoretical Methodology}

Consider a community of individuals $N$ indexed by $i \in N$. Let individual utility be given by a private utility function $u\left(x_{i}, g\right)$, where $x_{i}$ is a private good and $g$ is a public good. Individuals are assumed to care about the level of the public good enjoyed by others in the community but have no preference about distribution of the private good among others. For simplicity, assume that they have no other distributional concerns. In particular, assume that $i$ does not care about $x_{j}$ for $j \neq i$. This assumption of course requires assuming that the level of $x_{i}$ enjoyed by any individual $i$ is not connected to the level enjoyed by any other individual.

Let the distributional concerns related to the public good held by individual $i$ be represented by a citizen utility function $\theta_{i}\left(x_{i}, g\right)$. If the private and public goods are both normal, it follows that $\theta_{i}\left(x_{i}, g\right)>\theta_{i}\left(\tilde{x}_{i}, g\right)$ for $x_{i}>\tilde{x}_{i}$ and $\theta_{i}\left(x_{i}, g\right)>\theta_{i}\left(x_{i}, \tilde{g}\right)$ for $g>\tilde{g}$. However, there may be cases in which $u_{i}\left(x_{i}, g\right)>u_{i}\left(\tilde{x}_{i}, \tilde{g}\right)$ but $\theta_{i}\left(x_{i}, g\right)<\theta_{i}\left(\tilde{x}_{i}, \tilde{g}\right)$ for $x_{i}>x_{i}$ and $g<\tilde{g}$. When this is the case, the individual private benefit from the difference $x_{i}-x_{i}$ exceeds the loss from $g-\tilde{g}$, but the individual's concern about the impact of the change of $g$ on others in the community more than offsets it.

Let $x_{i}$ be a numeraire good, which we consider to be income, that is exogenously given relative to the public good level $g$. Now, consider a change in the level of the public good that must be financed by the community. 
Imagine that each individual is charged a tax $\tau_{i}$ and that the increase in the level of the public good is $\gamma$ The community engages in a deliberation process to determine the change in the public good and how much to pay to finance it. Following the same approach as Howarth and Wilson (2006), who rely on cooperative game theory, the gain to the community from a negotiated solution can be defined as:

$$
\Theta(\vec{\tau}, \gamma)=\prod_{i}^{n}\left(\theta_{i}\left(x_{i}-\tau_{i}, g+\gamma\right)-\theta_{i}\left(x_{i} g\right)\right)^{\lambda_{i}}
$$

Where $\lambda_{i}$ is a weight on the net increase in citizen utility for individual $i$ resulting from the tax and the change in the public good. We will assume that $\lambda_{i}$ is equal to one from here forward.

If we assume that the project is marginal, in the sense that the levels of $\tau_{i}$ and $\gamma$ are such that the derivatives $\partial \theta_{i} / \partial x_{i}$ and $\partial \theta_{i} / \partial g$ are unchanged, then we can write:

$$
\theta_{i}\left(x_{i}-\tau_{i}, g+\gamma\right)-\theta_{i}\left(x_{i}, g\right)=\gamma\left(\partial \theta_{i} / \partial g\right)-\tau_{i}\left(\partial \theta_{i} / \partial x_{i}\right)
$$

If we further define $w_{i}=\gamma\left(\partial \theta_{i} / \partial g\right) /\left(\partial \theta_{i} / \partial x_{i}\right)$, then we can write:

$$
\theta_{i}\left(x_{i}-\tau_{i}, g+\gamma\right)-\theta_{i}\left(x_{i}, g\right)=\left(w_{i}-\tau_{i}\right)\left(\partial \theta_{i} / \partial x_{i}\right)
$$

Notice that the ratio $\left(\partial \theta_{i} / \partial g\right) /\left(\partial \theta_{i} / \partial x_{i}\right)$ is the citizen shadow price of the change in environmental quality. Returning to the overall community welfare, we can write:

$$
\Theta(\vec{\tau}, \gamma)=\prod_{i}^{n}\left(w_{i}-\tau_{i}\right)\left(\partial \theta_{i} / \partial x_{i}\right)=\prod_{i}^{n}\left(\partial \theta_{i} / \partial x_{i}\right) \prod_{i}^{n}\left(w_{i}-\tau_{i}\right)=\alpha \prod_{i}^{n}\left(w_{i}-\tau_{i}\right)
$$

Where, on account of the fact that the project is marginal, $\alpha=\prod_{i}^{n}\left(\frac{\partial \theta_{i}}{\partial x_{i}}\right)$ is constant. Now, we turn to the question of how much the community would choose to contribute to paying for the increase $\gamma$ in the public good. Let $W$ be the total amount that the community will agree to provide and let $s_{i}$ be the share of this total that individual i pays, with $\sum_{i}^{n} s_{i}=1$. Then, we can write:

$$
\Theta=\alpha \prod_{i}^{n}\left(w_{i}-s_{i} W\right)
$$

Using this result, Howarth and Wilson (2006) are able to demonstrate that $\mathrm{W} \leq \Sigma_{n} w_{i}$, or that the community WTP is less than the sum of the individual citizen WTPs, with equality only when $w_{i} / s_{i}=w_{j} / s_{j}$ for all $i, j$. If $\partial \theta_{i} / \partial g>\partial u_{i} / \partial g$ and $\partial \theta_{i} / \partial x_{i}>\partial u_{i} / \partial x_{i}$, then the private shadow price for an increase in the public good is less than the citizen shadow value. This result is consistent with the construction that community members care about the public good enjoyed by others but there is no relationship between the community members regarding consumption of the private good $x_{i}$. Therefore, it is possible that $\mathrm{W} \geq \sum_{n} \widetilde{w}_{i}, \widetilde{w}_{i}=\gamma\left(\partial u_{i} / \partial g\right) /\left(\partial u_{i} / \partial x_{i}\right)$. If individuals have citizen preferences that are different from their private preferences, then a deliberation process could support projects for which the community WTP is greater than the sum of the private WTPs.

\section{Empirical Methodology}

\subsection{DCJ Procedures}

The DCJ participants were individuals who completed the general public survey and who showed interest in participating in the deliberation sessions. In the main survey, we asked participants to provide contact information and indicate their willingness to participate in a deliberation workshop. We also indicated that if there were more than 60 such volunteers, invited participants would be chosen at random. If there were less than 60 volunteers, all would be contacted and invited to participate. Out of 468 individuals who completed the general public survey, about $55(12 \%)$ showed interest, and all were invited to the DCJ sessions. Only 23 (42\%) participants actually attended. 
Step one was grouping volunteer participants into two jury sessions, group 1 and group 2, to meet over two days. Each jury session lasted 90 minutes and was coordinated by two facilitators. The jury sessions began with a briefing on the format and group norms, the fact that a choice experiment survey was implemented prior to these jury sessions, the fact that local environmental issues were identified through a discussion with Regional District of Central Okanagan (RDCO) experts and Okanagan residents, and the fact that pilot study results were used to prioritize environmental issues. Participants were also reminded that the "no action" status quo represented the continuation of the current environmental resources situation managed using the existing actions through 2040 and that this option does not involve any increase in a household's payment; that options 1 and 2 involved additional management actions that would lead to different environmental resources and services outcomes by 2040 and that these options had to be paid for, resulting in a reduction in available household income each year for 30 years; and that the funds would be saved in an account specific to this conservation project. The facilitator also informed participants that they would be spending some time talking about each of the four environmental indicators that they saw on the main survey, which were now presented differently in the form of decision challenges. Moreover, confidentiality issues were raised, and the "Vegas rules" were explained. The "Vegas rules" state that what happens during the session stays in the session. Each participant was required to respect the privacy of all other participants by not revealing the details of the session to any outsiders. All opinions expressed were to be taken as equally valid. Each participant had to treat all others with respect. All questions were to be considered valid and were answered in a respectful manner. After the session was over, participants were allowed to continue the discussions with anyone else.

Step two was an information session. Unlike in the case of standard deliberative juries, we presented the jury participants with video-recorded personal testimonies of locally recognized individuals who had chosen careers and risen into positions where they could influence environmental policy and decisions. The recorded interviews focused on these witnesses' perspectives on the environmental issues that formed the basis of the survey, their knowledge of these issues, and their personal histories and relationships to the environment. Specific details about the attributes were avoided. These citizens were identified from the networks of the research team and community partners, such as the Okanagan Basin Water Board, the Regional District of the Central Okanagan, and the city of Kelowna. The two jury groups then were given the opportunity to prepare up to two questions that were electronically delivered to the witnesses. The responses from the witness were read to the participants during the second session. The recorded interview presentations took about 20 minutes, and each group took 20 minutes to ask questions.

The third step was deliberation and the decision challenge. At this stage, facilitators replayed the expert answers back to the participants. Jury members were allowed to cross-question each other based on expert answers and other issues raised by participants during and in between the two sessions. The facilitators also avoided playing the role of experts. Rather, they turned the conversation back to the group, seeking to draw out personal experiences reflecting relationships with the environment. Participants were also motivated to suggest discussion issues related to each attribute.

The following attribute descriptions and facts suggested for discussion were read out loud among jurors for open discussion.

- Groundwater: Groundwater is an important source of water that we use and that supports springs and wetlands, which are important natural habitats. Increasing groundwater use threatens these habitats. Most surface sources in the Okanagan are fully allocated. Increasing the share of total use from groundwater also reflects an increase in overall water use and in the amount of groundwater used.

Suggestions for discussions: Facts on the depletion of springs; how they work; animals that depend on them; and how they have been changing in the Okanagan, particularly in the central Okanagan.

- Aquatic Habitat Health: Aquatic health is threatened by shoreline development, invasive species pollution, etc. Species such as Kokanee salmon are sensitive to the overall health of the aquatic environment. Since the 1970s, spawning Kokanee numbers in Okanagan Lake have fallen from over one million to about 40,000. Historic returns were much higher than they are today. The decline is partly due to failed efforts to enhance the Kokanee fishery. Protection and enhancement of spawning and rearing areas can help increase returns.

Suggestions for discussion: The facts about the salmon population, its life cycle, the role it plays in the local ecosystem, reasons that the population has declined, and things that can be done to enhance the its population.

- Natural Habitat Loss: Natural habitats, such as wetlands, forests, natural grasslands, etc. provide a range of environmental goods and services. The loss of these areas threatens the survival of some wild species within the Okanagan, and the loss of areas that allow the movement of these species threatens the health of their 
populations. These environmental resources and services are largely lost if the land is developed.

Suggestions for discussion: Important endangered species in the Okanagan; the problem of invasive species; the loss of natural habitat, particularly the valley bottom habitat; the importance of connectivity; how we lose more habitat; and how we lose options to connect to different areas.

- Rural Character: Rural areas have a unique character that reflects their history and close ties to the land. Increasing development and population growth in rural areas increases traffic, reduces the amount of open space, increases conflict between farmers and non-farm residents, and impacts natural habitats.

Suggestions for discussion: Facts about population growth, land development in rural areas, and changes in traffic volumes.

\subsection{Decision Challenge}

The fundamental idea behind the decision challenge is to attempt to combine the desirable features of the DCJ techniques with the particular requirements of economic valuation. We may call this method "Deliberative Market Stall" approach, inspired by Macmillan et al. (2002) "Market Stall" approach. This method, not only explicitly combine DCJ methods, but also produce WTP estimates. Hence, each participant was provided with two decision challenges inspired by the issues raised in the survey. In the main survey, participants faced 6 choice cards for different possible environmental futures with costs of achieving those futures. Figure 1 below which shows sample main survey choice Card.

In this exercise, jurors were required to consider and rank a few scenario combinations drawn from the choice scenarios and allocate funding for each attribute. The funding is to be collected and spent over 30 years. The total funding will be about $\$ 60$ million if $\$ 20$ levy is collected, or $\$ 120$ million if $\$ 40$ levy is collected per household per year for 30 years (the same payment amount they knew from the main survey). Figure 2 shows 60 million budget decision challenge choice card. These monetary figures were calculated considering the current and projected household size of 80,000 and 120,000 in Central Okanagan over the planning period. Hence, if \$20 million is spent to enhance Kokanee returns, we predict that returns will increase from 40,000 to 50,000. 


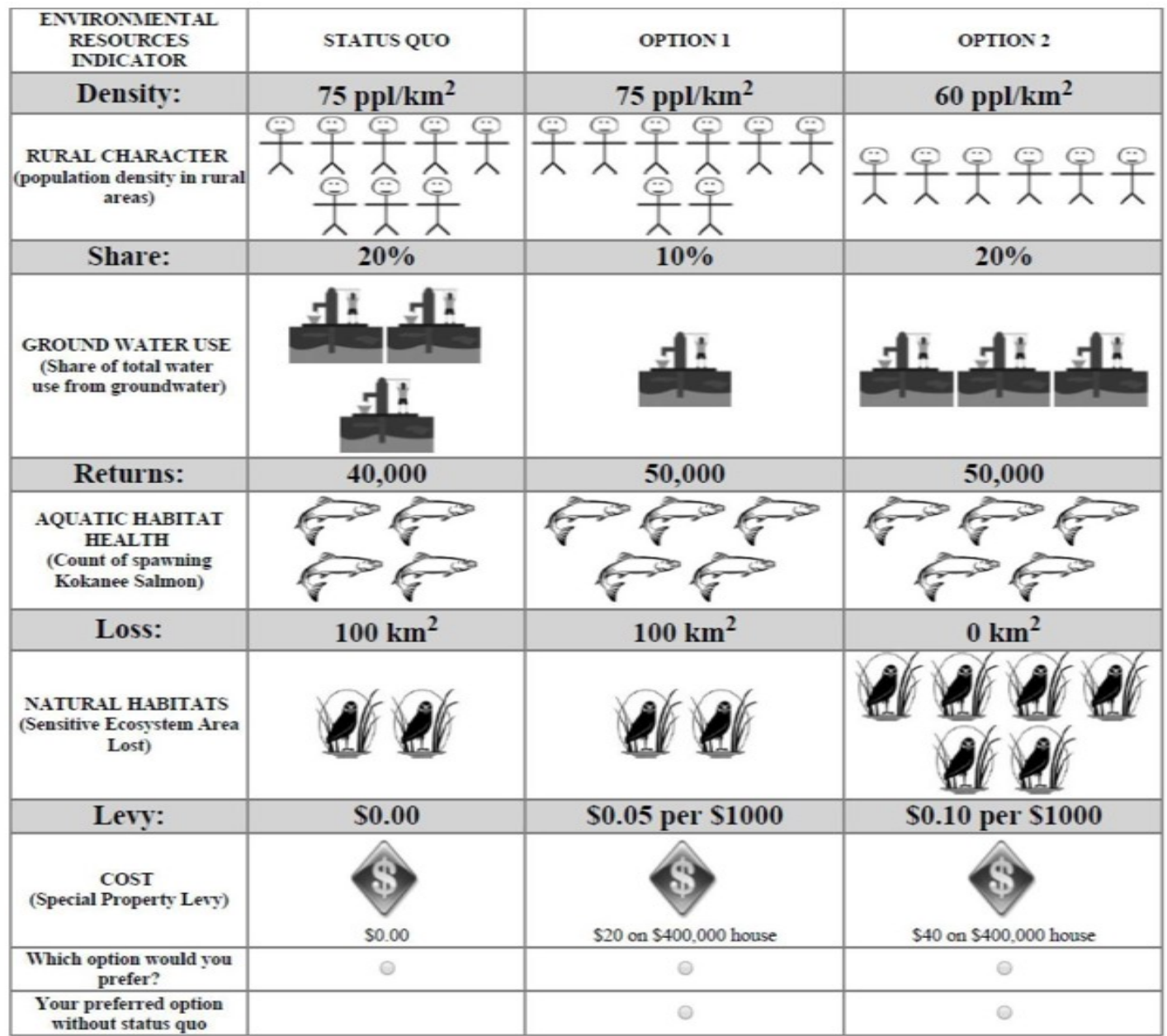

Figure 1. Sample stated choice screen

If $\$ 40$ million is spent, returns will increase to 60,000 . Therefore, jurors were required, as a group, to tell us how they would divide $\$ 60$ million budget, and how they would divide $\$ 120$ million budget, between four attribute categories. In one possibility, they could spend $\$ 20$ million to increase Kokanee returns to 50,000, another $\$ 20$ million to reduce natural habitat loss to $50 \mathrm{~km}^{2}$, and a further $\$ 20$ million to keep rural population density at 70 people $/ \mathrm{km}^{2}$, for a total of $\$ 60$ million. In another possibility, they could spend $\$ 40$ million to increase Kokanee returns to 60,000 and $\$ 20$ million to reduce natural habitat loss, with nothing spent to limit rural population growth or groundwater use. They were given 15 minutes to discuss the choices, reflect on the issues raised, expert witnesses reflections and answers to questions asked and other related issues and 45 minutes to work with their group to arrive at an agreed way of dividing the budget between the categories. 


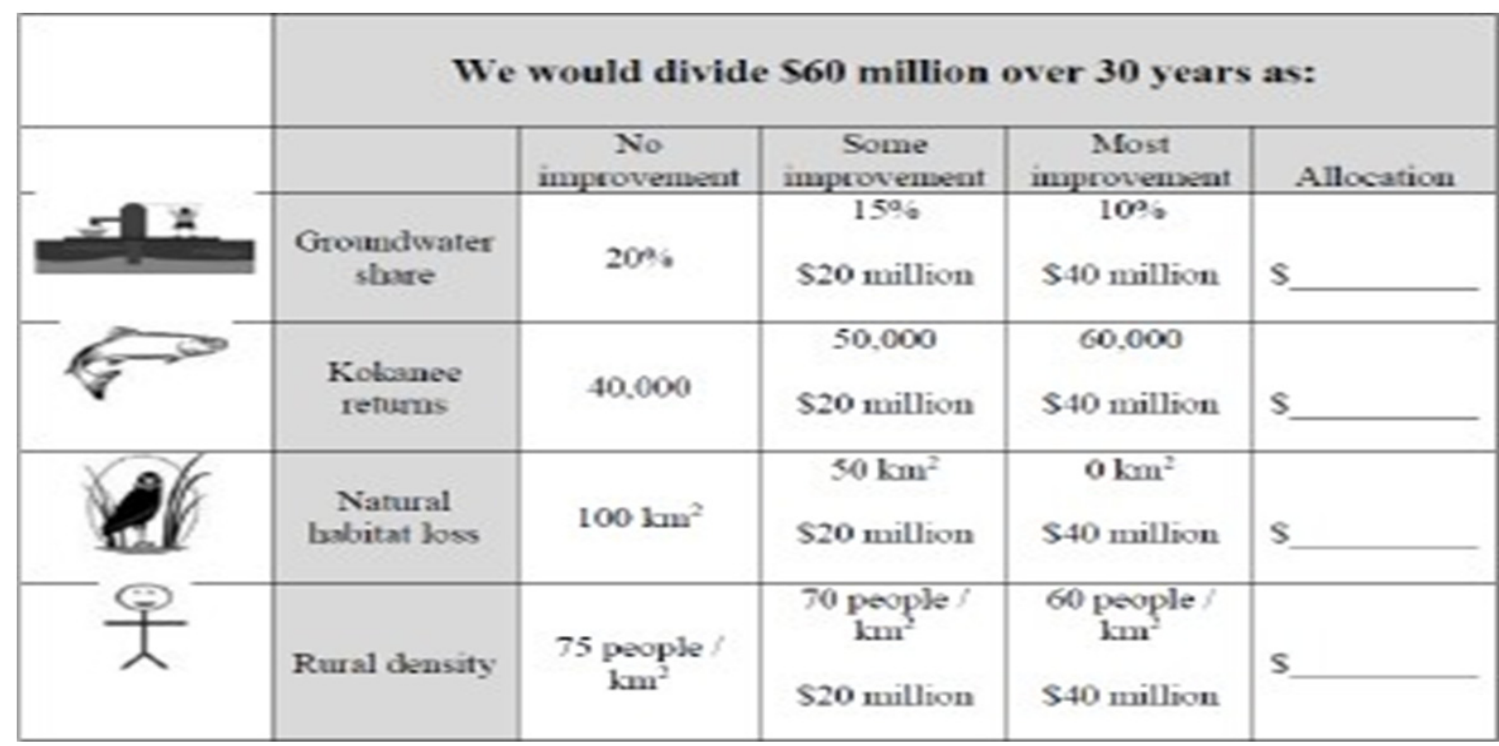

Figure 1. Decision Challenge Card: Decision Challenge Choice Card 1. Participants were required to allocate $\$ 0$, $\$ 20$ or $\$ 40$ million to each category in the allocation column. The total of the entries in that column could not exceed $\$ 60$ million. Within any category, going from no improvement to some improvement cost $\$ 20$ million over 30years. Within any category, going from no improvement to the greatest improvement cost $\$ 40$ million over 30 years

The final decision was done by mutual consent unlike the majority rule collective decision mechanism used in many DCJ exercises (A' lvarez-Farizo \& Hanley, 2006; Coote \& Lenaghan, 1997). After group allocation exercise was completed, jury members completed a secret ballot where each could choose differently from the group choice. A debriefing exercise was also conducted at the end of group exercise to see how participants understood the approach as a means of establishing preference and WTPvalues. The sessions were conducted on February 20, 21, and 22 at the RDCO office conference hall. After these sessions were completed, both the DCJ participants and those who did not participate on the DCJ were invited to complete a shortened version of the original choice experiment (CE). This process was intended to help us understand if the amount participants are willing to pay to protect the environment changes in response to participation in the deliberation process.

\subsection{Econometric Model}

\subsubsection{The Random Parameter Logit Models (RP)}

We need to determine whether there is any significant difference in preferences after people have had chances to receive more information and to think collectively as citizens rather than individually as consumers through discussions among the jurors, family, and friends (A' lvarez-Farizo et al., 2009; A' lvarez- Farizo \& Hanley, 2006). This change of preference is examined econometrically by testing whether the DCJ system has any influence on the heterogeneity of opinions. In other words, we examine if the expressed preferences that result from the deliberation process are measurably different than those people who did not engage in deliberation. It suggests community values when heterogeneity in responses decrease in the DCJ sessions (i.e. among the deliberation sample) compared to the control and main survey samples (A' lvarez-Farizo \& Hanley, 2006). This may be possible with models such as the Random Parameter Logit Models (RP) and Latent Class models (LC). We use the RP model to see if there is a decrease in heterogeneity as we move from traditional CE to DCJ decision challenge choices format.

We formalize the RP model following from Revelt and Train (1998). Let $N$ represent a sample of respondents with the choice of $J$ alternatives on $T$ choice occasions. Individual $i$ 's $(i=\ldots, N)$ utility function, from choosing alternative $j$ on choice occasion $t$ may take the following form:

$$
U_{i j t}=V_{i j t}+E_{i j t} \Rightarrow \beta_{j} x_{i j t}+\gamma_{i} z_{i t}+E_{i j t}
$$

where $\beta_{j}$ is a vector coefficient of attributes relating to individual $i$ and alternative $j$ on choice occasion $t, x_{i j t}$ is 
observable attributes of the alternatives, $\gamma_{i}$ is individual specific coefficients relating to individual $i$ 's characteristics, $z_{i t}$ is observable individual specific characteristics and $E_{i j t}$ is a random term that is assumed to be an independently and identically distributed extreme value. The $\beta_{j}$ coefficients vary over decision makers with density $f(\beta \mid \theta)$, where $\theta$ are the parameters of the distribution. Assuming that the decision maker knows the value of his own $\beta_{j}$ and $E_{i j t}$ for all $j$, he will choose alternative $k$ if and only if $V_{i j t}>V_{i k t}, \forall k \neq j$. If the parameter $\beta_{j}$ is known, the choice probability would take the standard logit form:

$$
P_{i j t}=\frac{\exp \left(\beta^{\prime}{ }_{j} x_{i j t}\right)}{\sum_{j=1}^{J} \exp \left(\beta^{\prime}{ }_{j} x_{i j t}\right)}
$$

If the parameter $\beta_{j}$ is not known, the RP unconditional choice probability is the integral of $\mathrm{P}_{i j t}$ over all possible variables of $\beta_{j}$ and takes the following form:

$$
P_{i j t}=\int\left(\frac{\exp \left(\beta^{\prime}{ }_{j} x_{i j t}\right)}{\sum_{j=1}^{J} \exp \left(\beta^{\prime}{ }_{j} x_{i j t}\right)}\right) f(\beta \mid \theta) d \beta
$$

where $f(\beta \mid \theta) d \beta$ is the density function of $\beta$. We know that survey participants are making repeated choices and that the probability of a sequence of choices may given by (Hole,2007):

$$
P_{i j t}=\int \prod_{t=1}^{T} \prod_{j=1}^{J}\left[\frac{\exp \left(\beta^{\prime}{ }_{j} x_{i j t}\right)}{\sum_{j=1}^{J} \exp \left(\beta^{\prime}{ }_{j} x_{i j t}\right)}\right]^{y_{i j t}} f(\beta \mid \theta) d \beta
$$

where $\mathrm{y}_{i j t}=1$ if the individual chose alternative $j$ in choice situation $t$ and 0 otherwise. These probabilities are approximated by maximizing the $\theta$ parameters through the simulation of the log-likelihood function. Hence, the average simulated probability may take the following form:

$$
P_{i j t}=\sum_{i=1}^{N} \ln \left\{\frac{1}{R} \sum_{1}^{R} \prod_{t=1}^{T} \prod_{j=1}^{J}\left[\frac{\exp \left(\beta^{[r]}{ }_{j} x_{i j t}\right)}{\sum_{j=1}^{J} \exp \left(\beta^{[r]}{ }_{j} x_{i j t}\right)}\right]^{y_{i j t}}\right\}
$$

where $\mathrm{R}$ is the number of $\beta$ draws of from $f(\beta \mid \theta)$ and where $\beta_{j}{ }^{[r]}$ is the $r^{\text {th }}$ draw for individual i from the distribution of $\beta$. The implication is that we are allowing for the fact that different decision makers may have different preferences and that the independence of irrelevant alternatives property no longer holds (Hole, 2007). Equations like (9) and (10) are called RP probabilities (Revelt \& Train, 1998). The general specification allows fitting models with both individual-specific and alternative-specific explanatory variables (Hole, 2007). The maximum simulated likelihood estimator is the value of $\theta$ that maximizes $P_{i j t}$ (Hole, 2007; Revelt \& Train, 1998).

\subsubsection{Propensity Score Matching}

The first task is to remove any significant differences between the individuals who participated in the DCJ (treatment sample), or those who participated in the DCJ sessions and also completed the survey a second time, and the non-treated individuals (control sample), or those who took the survey twice but did not volunteer to be part of the DCJ, in terms of the baseline socioeconomic characteristics shown in Table 1 below. 
Table 1. Baseline socioeconomic covariates

\begin{tabular}{|c|c|c|}
\hline Age Group & Frequency & Percent \\
\hline Young & 18.00 & 0.87 \\
\hline Lower Middle Age & 396.00 & 19.13 \\
\hline Upper Middle Age & 918.00 & 44.35 \\
\hline Senior Age & 738.00 & 35.65 \\
\hline \multicolumn{3}{|l|}{ Income Group } \\
\hline Lower Income & 216.00 & 10.43 \\
\hline Lower Middle Income & 846.00 & 40.87 \\
\hline Upper Middle Income & 828.00 & 40.00 \\
\hline High Income & 180.00 & 8.70 \\
\hline \multicolumn{3}{|l|}{ Education Group } \\
\hline Completed High School/Below & 288.00 & 13.91 \\
\hline Have Diploma/Attended Univ & 702.00 & 33.91 \\
\hline University Degree/Above & 1080.00 & 52.17 \\
\hline \multicolumn{3}{|l|}{ Household Characteristics } \\
\hline Couple with children living at home & 504.00 & 24.35 \\
\hline Couple with children who have left home & 846.00 & 40.87 \\
\hline Couple with no children & 288.00 & 13.91 \\
\hline Group household/Sharing with friends & 54.00 & 2.61 \\
\hline Living alone & 324.00 & 15.65 \\
\hline Single parent with children living at hom & 54.00 & 2.61 \\
\hline \multicolumn{3}{|l|}{ Property tax Responsibility } \\
\hline Jointly or solely & 1980.00 & 95.65 \\
\hline Not Responsible & 90.00 & 4.35 \\
\hline \multicolumn{3}{|l|}{ Gender } \\
\hline Female & 684.00 & 33.04 \\
\hline Male & 1386.00 & 66.96 \\
\hline \multicolumn{3}{|l|}{ Dwelling Owner } \\
\hline Rented & 234.00 & 11.30 \\
\hline Own/partner & 1836.00 & 88.70 \\
\hline Total & 2070.00 & 100.00 \\
\hline
\end{tabular}

Removing these differences allows us to attribute the changes in preferences to the deliberation treatment only. The standard approach for estimating the effects of the intervention (deliberation treatment) on the probability of choosing conservation outcomes would be a randomized controlled trial (Austin, 2011). However, our data is observational. We suspect there is a treatment selection problem (self-selection) and that the result may be influenced by subject characteristics. In other words, the baseline characteristics of those who attended the DCJ sessions may differ from those of the control sample. We overcome this issue using the propensity score matching (PSM) method. The PSM method forms matched sets of treated and non-treated subjects who share similar propensity score values (Rosenbaum \& Rubin, 1983). The propensity score is a balancing score in a sense that the distributions of measured baseline observed predictors are similar between treated and non-treated subjects (Austin, 2011). Thus, the effect of deliberation on conservation option choices can be estimated by comparing the outcomes directly between the two subjects (Greenland, Pearl, \& Robins, 1999). The procedure in the PSM method is to check the overlaps and the regions of common support between the treatment and control 
samples. One of the different methods suggested in the literature is a visual analysis of the density distributions of the propensity scores in both groups (Caliendo \& Kopeinig, 2008). This method is easier in the sense that the support problem can be spotted by inspecting the propensity score distribution, so we may not need to implement a complicated formal estimator (Lechner, 2000).

The more formal approach is comparing the minima and maxim a of the propensity scores in both groups (Caliendo \& Kopeinig, 2008). Then, we delete all observations whose propensity scores are smaller than the minimum or larger than the maximum in the other group (Caliendo \& Kopeinig, 2008). For instance, if the propensity score lies within the interval $[0.06,0.84]$ in the treatment group and within $[0.04,0.90]$ in the control group, the common support is given by $[0.06,0.84]$ (Caliendo \& Kopeinig, 2008). "The idea of implementing the common support condition is to ensure that any combination of characteristics observed in the treatment group can also be observed among the control group (Caliendo \& Kopeinig, 2008)." Thus, the propensity score values in the common support region can be interpreted as the predicted probability of a member of the control group being selected into the treatment group. For example, if the propensity score of a control sample respondent is 0.7 , it means that she/he has a $70 \%$ chance of being selected to the treatment group. Intuitively, we want the control group to perfectly overlap or look very similar to the treatment sample in terms of individual background characteristics or covariates.

Using logistic regression and applying the Stata psmatch package (StataCorp et al., 2013), we estimate propensity scores on the observed covariates listed in Table 1 above. We see (Table 2) that propensity scores lie between $[0.02,0.70]$, implying that the observations that lie outside of this region can be discarded from analysis. We also see from Figure 3 that the propensity scores in the deliberation and control samples do not overlap perfectly, implying systematic differences in the baseline characteristics of the deliberation participants and non-participants.

Table 2. Estimated propensity score results in the region of common support

\begin{tabular}{lllll}
\hline & Percentiles & Smallest & & Percentiles Largest \\
\hline $1 \%$ & 0.023415 & 0.023415 & $75 \%$ & 0.2928530 .686780 \\
$5 \%$ & 0.031324 & 0.023415 & $90 \%$ & 0.4191610 .686780 \\
$10 \%$ & 0.045892 & 0.023415 & $95 \%$ & 0.5591720 .686780 \\
$25 \%$ & 0.093343 & 0.023415 & $99 \%$ & 0.6716580 .686780 \\
$50 \%$ & 0.154178 & & & \\
\hline Mean & & & 0.20536 \\
Std. Dev. & & & 0.1537 \\
Variance & & & 0.02362 \\
Skewness & & & 1.13088 \\
Kurtosis & & & 3.7912 \\
\hline
\end{tabular}




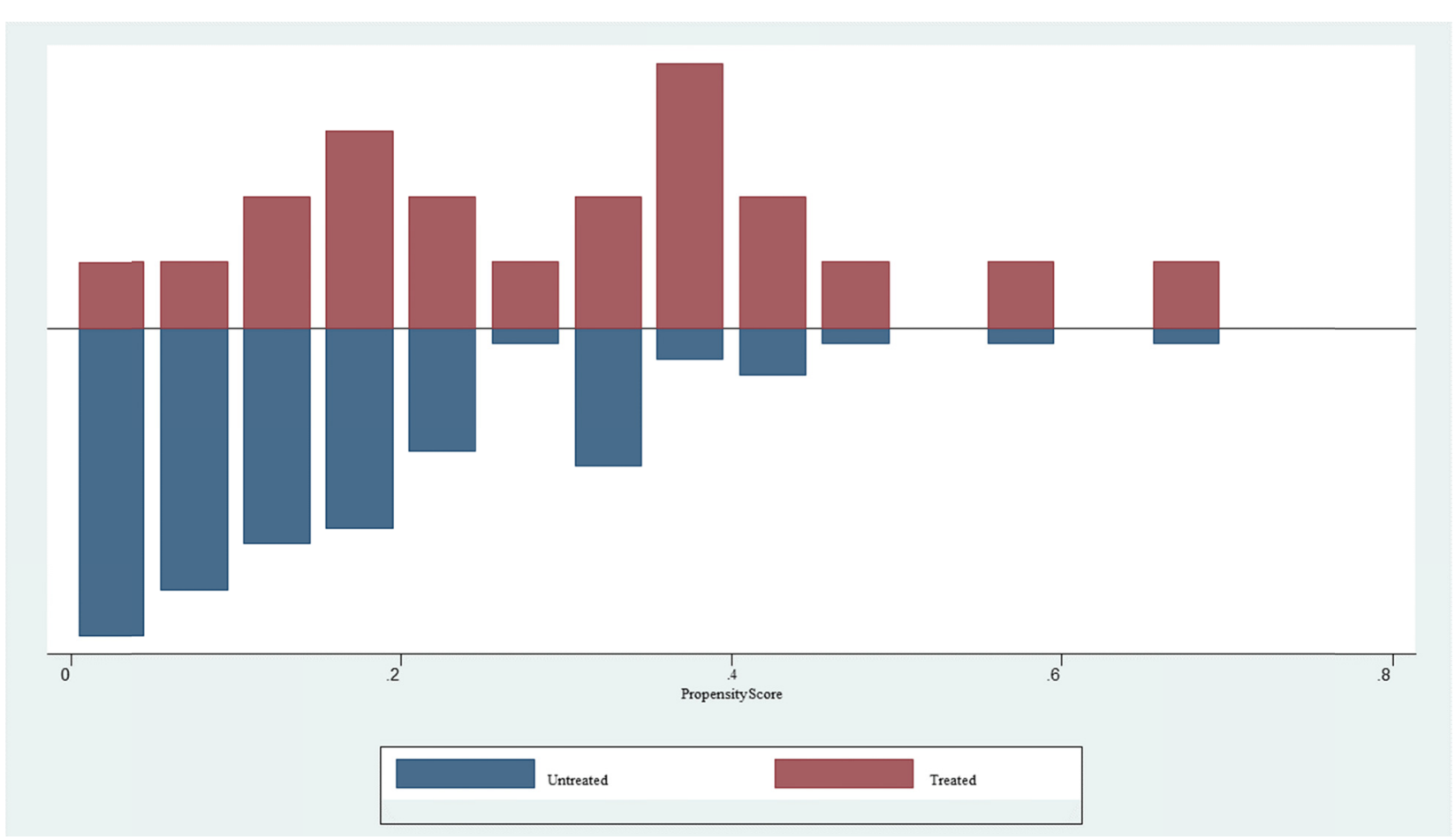

Figure 3. Treatment and control group overlap

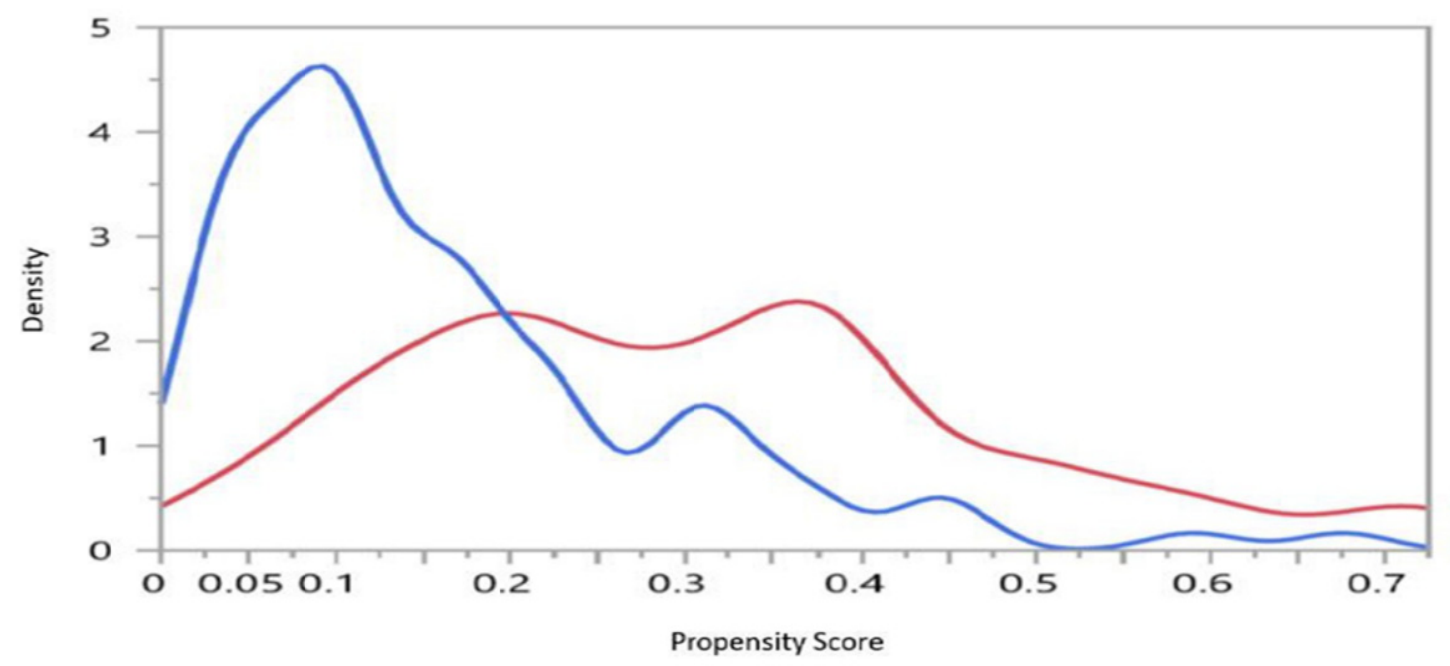

Figure 4. Estimated propensity score distribution

Using the estimated propensity score results in the region of common support information $[0.02,0.70]$ and the overlapping distribution of the groups, we created a new control group that is relatively similar to the treatment group. We sed a benchmark of a $20 \%$ propensity score value to include a respondent in the new control group because individuals with scores above $20 \%$ are more similar in the region of common support. Hence, individuals with scores below 20\% were excluded (See Figure 4 for the estimated propensity score distribution and the 20\% cutoff point). We apply this exclusion because, on average, treated and non-treated participants have similar distributions of measured baseline covariates above a propensity score of $20 \%$. In other words, after matching, observed systematic differences between treated and untreated participants appear to have been greatly reduced 
(Rosenbaum \& Rubin, 1984), and the new control group (after removing participants with propensity scores below $20 \%$ ) looks very much like the treatment group.

Therefore, there is a smaller chance that systematic differences between the participants that are correlated with the variables we have observed cause any significant differences that we find in the conservation options choices.

\section{Results}

\subsection{Deliberation Effect}

Multinomial logit models (MNL) do not allow us to test whether the DCJ system has any influence on the heterogeneity of choice options. In other words, MNL models cannot show whether DCJs can be used to elicit community values as opposed to individual values. Community values are identified when the heterogeneity in responses decreases in the DCJ sessions (i.e., among the treatment sample) relative to the control and main survey samples (A' lvarez-Farizo et al., 2009). Such identification is possible with models like RP models, which can test for heterogeneity in certain attributes. We compare how both preferences and response heterogeneities behave using the RP model estimates for the deliberation, control, and main survey samples. Table 3 displays the result.

From the DCJ estimates in Table 3 (columns 2 and 3), we see that the parameter estimate on "Option 1" (the alternative-specific intercept) is statistically significant and has the expected sign. This result means that, on average, DCJ participants prefer Option 1 to the "no action" status quo alternative. The parameters on the alternative-specific coefficients (attributes) are not statistically significantly different from zero. However, they all have the expected sign. The coefficients on the standard deviations (SDs) of the alternative-specific intercepts are not statistically significant, implying that there is no preference heterogeneity in the data and that individuals are indifferent in tests between the two conservation options relative to the "no action" status quo option. However, from the magnitudes of the SDs relative to the mean coefficients, practically all participants prefer "Option 1" and about 6\% prefer "Option 2" over the "no action" status quo alternative. This figure is given by $100 \times \Phi\left(-\beta_{k} / \sigma_{k}\right)$, where $\Phi$ is the cumulative standard normal distribution and $\beta_{k}$ and $\sigma_{k}$ are the mean and SD, respectively, of the $k^{\text {th }}$ coefficients (Hole, 2007). This result is the expected outcome in the sense that the two choices are fundamentally similar in terms of the absolute change in attribute levels. Therefore, with deliberation, individuals are more informed, and "Option 1" is more attributive in terms of its lower average cost advantage over choice repetitions. Moreover, the variance covariance coefficients on some of the attributes are statistically significant (see Table 4), implying that the variables are not independent of each other and that those who chose an option with a higher salmon return, for instance, necessarily also want a decrease in the use of groundwater, a sensitive ecosystem protected (in terms of the decrease in habitat loss), and the unique rural character sustained.

Columns 4 and 5 in Table 3 show the results from the control sample. We see that all of the parameter estimates have the expected sign. The estimates on the alternative-specific coefficients (options 1 and 2) are statistically significant. The coefficients on the SDs of these variables are not statistically significant, implying that there is no evidence to support the increase in preference heterogeneity relative to the DCJ sample, in contrast to our expectation. However, from the magnitudes of the SDs relative to the mean coefficients, individuals are indifferent between the two improved options, unlike in the DCJ sample, in which "Option 1" was overwhelmingly chosen compared to the "no action" status quo alternative, suggesting some deliberation effect. The SD of cost is highly statistically significant, implying that cost is an important decision variable and that an increase in the cost of any of the conservation options reduces that options' utility. This result means cost has disutility, per theory and expectation. On the other hand, the SD coefficients on the habitat loss attribute are statistically significant, unlike in the DCJ model, suggesting some evidence for response heterogeneity in the data and that individuals react differently to changes in the levels of the attributes of each option. In addition, unlike in the DCJ case, attributes do not covary (see Table 5), suggesting that individuals only consider changes in the level of the attribute of interest, independent of other environmental attributes, in their conservation option decisions. This result is expected in the sense that private valuations should prevail among the control sample, whereas deliberation is expected to increase the extent to which participants consider community or group values. 
Table 3. Change in preferences before and after deliberation

\begin{tabular}{|c|c|c|c|c|c|c|}
\hline \multirow{2}{*}{ Variable } & \multicolumn{2}{|c|}{ DCJ Sample } & \multicolumn{2}{|c|}{ Control Sample } & \multicolumn{2}{|c|}{ Main Survey Sample } \\
\hline & Mean & SD & Mean & SD & Mean & SD \\
\hline \multirow[t]{2}{*}{$\beta^{1}[$ Option 1] } & $3.950^{*}$ & 0.45 & $3.305 * * *$ & 0.412 & $2.922 * * *$ & $1.436^{* * *}$ \\
\hline & $(-2.45)$ & $(-0.46)$ & $(-3.38)$ & $(-0.3)$ & $(-11.22)$ & $(-5.63)$ \\
\hline \multirow[t]{2}{*}{$\beta^{2}$ [Option 2] } & 2.368 & 1.512 & $2.530 * *$ & 0.353 & $2.224 * * *$ & $1.728^{* * *}$ \\
\hline & $(-1.71)$ & $(-1.81)$ & $(-2.83)$ & $(-0.65)$ & $(-8.83)$ & $(-8.32)$ \\
\hline \multirow[t]{2}{*}{$\beta_{2}[$ Ground water $]$} & 0.0541 & 0.164 & 0.00307 & 0.11 & -0.0098 & $0.119 * * *$ \\
\hline & $(-0.68)$ & $(-1.55)$ & $(-0.06)$ & $(-1.34)$ & $(-0.63)$ & $(-5.23)$ \\
\hline \multirow[t]{2}{*}{$\beta_{3}[$ Aquatic Health $]$} & 0.0619 & 0.0106 & 0.035 & 0.06 & $0.0000286^{* * *}$ & $0.0000459 * * *$ \\
\hline & $(-1.71)$ & $(-0.22)$ & $(-1.07)$ & $(-1.04)$ & $(-3.55)$ & $(-3.55)$ \\
\hline \multirow[t]{2}{*}{$\beta_{3}[$ Habitat Loss $]$} & -0.00904 & -0.0092 & -0.0083 & $0.0186^{* *}$ & $-0.0102 * * *$ & $0.0210 * * *$ \\
\hline & $(-1.21)$ & $(-0.71)$ & $(-1.38)$ & $(-2.66)$ & $(-5.46)$ & $(-9.21)$ \\
\hline \multirow[t]{2}{*}{$\beta_{5}[$ Rural Character $]$} & -0.0362 & 0.222 & -0.0489 & 0.0603 & -0.0182 & $0.101 * * *$ \\
\hline & $(-0.52)$ & $(-1.63)$ & $(-1.22)$ & $(-0.57)$ & $(-1.68)$ & $(-5.92)$ \\
\hline \multirow[t]{2}{*}{$\beta_{6}[\operatorname{Cost}]$} & -0.0288 & $0.119^{*}$ & -0.0602 & $0.173^{* *}$ & $-0.0395 * * *$ & $0.152 * * *$ \\
\hline & $(-0.66)$ & $(-2.51)$ & $(-1.56)$ & $(-3.15)$ & $(-3.85)$ & $(-13.86)$ \\
\hline Log likelihood & \multicolumn{2}{|l|}{96.41147} & \multicolumn{2}{|l|}{-158.54} & \multicolumn{2}{|l|}{-2097.9} \\
\hline$\chi^{2}$ & \multicolumn{2}{|l|}{45.31} & \multicolumn{2}{|l|}{133.2} & \multicolumn{2}{|l|}{1630.8} \\
\hline Prob $>\chi^{2}$ & \multicolumn{2}{|l|}{0.0000} & \multicolumn{2}{|l|}{0.0000} & \multicolumn{2}{|l|}{0.0000} \\
\hline $\mathrm{N}$ & \multicolumn{2}{|l|}{396} & \multicolumn{2}{|l|}{648} & \multicolumn{2}{|l|}{8424} \\
\hline \multicolumn{7}{|c|}{$\mathrm{t}$ statistics in parentheses } \\
\hline$* \mathrm{p}<0.05$ & $* * \mathrm{p}<0.01$ & $* * * \mathrm{p}<0.001$ & & & & \\
\hline
\end{tabular}

Table 4. Variance covariance of normally distributed coefficients: Deliberation sample

\begin{tabular}{llllll}
\hline & Groundwater & Aquatic Health & Habitat Loss & Rural Character & Cost \\
\hline$\beta_{2}[$ Ground water $]$ & $0.361^{*}$ & & & & \\
& $(-2.49)$ & & & & \\
$\beta_{3}[$ Aquatic Health $]$ & $-0.151^{*}$ & 0.0299 & & & \\
& $(-2.29)$ & $(-0.8)$ & & & \\
$\beta_{4}[$ Habitat Loss $]$ & $0.0521^{* *}$ & -0.000208 & 0.0156 & & \\
& -2.69 & $(-0.02)$ & $(-1.27)$ & & \\
$\beta_{5}[$ Rural Character $]$ & 0.0282 & $-0.290^{* *}$ & 0.0299 & 0.0787 & \\
& $(-0.34)$ & $(-2.61)$ & $(-0.32)$ & $(-0.75)$ & $-0.0583 *$ \\
$\beta_{6}[$ Cost $]$ & 0.0908 & -0.0533 & 0.0602 & -0.0181 & $(-2.33)$ \\
\hline $\mathrm{t}$ statistics in parentheses & $(-1.78)$ & $(-1.32)$ & $(-1.4)$ & $(-0.50)$ & \\
$* \mathrm{p}<0.05$ & $* * \mathrm{p}<0.01$ & $* * * \mathrm{p}<0.001$ & - & - & \\
\hline
\end{tabular}


Table 5. Variance covariance of normally distributed coefficients: Control sample

\begin{tabular}{llllll}
\hline & Groundwater & Aquatic Health & Habitat Loss & Rural Character & Cost \\
\hline$\beta_{2}[$ Groundwater $]$ & $0.170^{* *}(2.58)$ & & & & \\
$\beta_{3}[$ Aquatic Health $]$ & -0.0378 & $0.0717^{*}$ & & & \\
& $(-0.98)$ & $(-1.98)$ & & & \\
$\beta_{4}[$ Habitat Loss $]$ & -0.00668 & -0.0101 & $0.0190^{*}$ & & \\
& $(-0.83)$ & $(-1.34)$ & $(-2.49)$ & & \\
$\beta_{5}[$ Rural Character $]$ & 0.072 & -0.0863 & 0.0829 & 0.0252 & $(-0.48)$ \\
\multirow{2}{*}{$\beta_{6}[$ Cost $]$} & $(-1.58)$ & $(-1.82)$ & $(-1.95)$ & 0.0222 & $0.0761^{* *}$ \\
& -0.0478 & -0.012 & -0.0253 & $(-2.65)$ \\
\hline $\mathrm{t}$ statistics in parentheses & $(-1.59)$ & $(-0.43)$ & $(-1.10)$ & $(-0.83)$ & \\
$* \mathrm{p}<0.05$ & $* * \mathrm{p}<0.01$ & $* * * \mathrm{p}<0.001$ & - & - & - \\
\hline
\end{tabular}

From the main survey sample result in Table 3, the mean coefficients on the alternative-specific variables (options 1 and 2) are statistically significant. The coefficients on the attributes are also statistically significant, except for those on groundwater use and rural character, implying that most of these attributes are important conservation choice decision variables. The coefficients on the SDs are highly statistically significant, suggesting strong evidence for preference and response heterogeneity in the data. In other words, individuals have different tests for conservation options and also react differently to changes in the levels of the attributes relative to both the DCJ and control samples. The cost attribute has the expected sign (negative) and is highly statistically significant, as expected, meaning that an increase in the cost of any of the conservation options reduces that options' utility. Cost is not an important decision variable in the DCJ and control sample cases, implying that the utilities of the options do not depend on it. This result is expected because discussion enhances deliberative solutions as opposed to private solutions. In deliberative exercises, "the common good prevails and predictions of models based on narrow self-interest and negotiation may fail" (Mendelberg, 2002).

The variance covariance coefficients on the survey sample attributes are statistically significant, implying that individuals do evaluate the environment as a whole and that the attributes are not independent of each other. This outcome is similar to the DCJ case, in which the environmental attributes are statistically significantly correlated, in contrast to the control sample outcome (see Table 6).

Table 6. Variance covariance of normally distributed coefficients: Main survey sample

\begin{tabular}{llllll}
\hline & Groundwater & Aquatic Health & Habitat Loss & Rural Character & Cost \\
\hline$\beta_{2}[$ Groundwater $]$ & $0.134^{* * *}$ & & & & \\
& $(6.54)$ & & & & \\
$\beta_{3}[$ Aquatic Health $]$ & -0.0000165 & $-0.0000603^{* * *}$ & & & \\
& $(-1.29)$ & $(-6.31)$ & & & \\
$\beta_{4}[$ Habitat Loss $]$ & $0.0181^{* * *}$ & $0.0144^{* * *}$ & $-0.0116^{* * *}$ & & \\
& $(-6.03)$ & $(-5.33)$ & $(-3.62)$ & & $0.0868^{* * *}$ \\
$\beta_{5}[$ Rural Character $]$ & -0.000924 & -0.0247 & $-0.0731^{*}$ & $0.0780^{*}$ & $(-12.38)$ \\
& $(-0.06)$ & $(-1.39)$ & $(-2.53)$ & $(-2.5)$ & -0.0182 \\
$\beta_{6}[$ Cost $]$ & $0.0280^{*}$ & 0.00341 & 0.00488 & $(-1.06)$ & - \\
\hline $\mathrm{t}$ statistics in parentheses & $(-2.41)$ & $(-0.34)$ & $(-0.42)$ & & \\
$* \mathrm{p}<0.05$ & $* * \mathrm{p}<0.01$ & $* * * \mathrm{p}<0.001$ & - & & \\
\hline
\end{tabular}


One of the questions here (motivated by Álvarez-Farizo and Hanley (2006)) is whether "preference changes are statistically significant across DCJ, control and main survey samples." To address this question, we test the null hypothesis of the equality of the parameter coefficients across the DCJ, control and main survey samples. Formally, the null and alternative hypotheses take the following form:

$$
\begin{aligned}
& H_{0}: \beta_{i} \text { (Deliberation) }=\beta_{i}(\text { Control })=\beta_{i} \text { (Main Survey) } \\
& H_{1}: \beta_{i} \text { (Deliberation) } \neq \beta_{i}(\text { Control }) \neq \beta_{i} \text { (Main Survey) }
\end{aligned}
$$

The likelihood-ratio test statistic (LRT) of this hypothesis is the ratio of the likelihood of the simpler attribute-only model with fewer parameters and the broader model with alternative-specific intercepts.

$$
\mathrm{LRT}=-2 \log \left(\mathcal{L}_{\text {Attribute only }}(\widehat{\theta})\right) /\left(\mathcal{L}_{\text {Attribute }+ \text { Intercepts }}(\widehat{\theta})\right)
$$

Asymptotically, the test statistic is distributed as a chi-squared random variable with degrees of freedom equal to the difference in the number of parameters between the two models ( $A^{\prime}$ lvarez-Farizo \& Hanley, 2006; Greene, 2012). Table 7 shows this test statistic.

Table 7. Likelihood ratio tests

\begin{tabular}{llll}
\hline & \multicolumn{1}{c}{ LL $_{\text {Attribute Only }}$} & \multicolumn{1}{c}{$L L_{\text {Attribute }+ \text { Intercept }}$} & LRT \\
\hline$L R$ treatment & -103.0855 & -96.5566 & 13.0577 \\
$L R$ Control & -165.3333 & -158.3627 & 13.9412 \\
$L R$ Main Survey & -2322.7199 & -2100.4806 & 444.4786 \\
$L R_{T C}=\beta_{T}($ Treatment $)=\beta_{C}($ Control $)$ & -165.3333 & -96.5566 & 137.55346 \\
$L R_{T M}=\beta_{T}($ Treatment $)=\beta_{M}($ Main survey) $)$ & -2322.7199 & -96.5566 & 4452.3266 \\
$L R_{C M}=\beta_{C}($ Control $)=\beta_{M}$ (Main survey) & -2322.7199 & -158.3627 & 4328.71434 \\
\hline
\end{tabular}

We see from the table that we can not accept the null hypothesis of parameter equality across the different survey samples and choice models, as the likelihood-ratio test statistic values are above the critical $\chi^{2}$ value of 11.070 for five degrees of freedom at the $\alpha=0.05$ significance level. The other important main question is if preferences change significantly within the same sample before and after deliberation (among the treatment sample) and before and after completing the survey the second time (among the control sample). This analysis is demonstrated in Table 8 .

We see from Table 8 that there is relatively more heterogeneity in the data before deliberation than after deliberation. We see that the SDs of the alternative-specific intercepts (Option 1) and attribute coefficients (groundwater and habitat loss) are statistically significant, implying preference and response heterogeneity in the data at a $95 \%$ confidence level among the treatment sample before deliberation. Choices are consistent among the control sample, implying that completing the survey the second time did not matter or did not change participants' preferences. 
Table 8. Changes in preferences before and after deliberation (Treatment sample) and between the first and second time participating in the survey (Control sample)

\begin{tabular}{|c|c|c|c|c|c|c|c|c|}
\hline & \multicolumn{2}{|c|}{ Before Deliberation } & \multicolumn{2}{|c|}{ After Deliberation } & \multicolumn{2}{|c|}{ Control (First Time) } & \multicolumn{2}{|c|}{ Control (Second Time) } \\
\hline & Mean & SD & Mean & SD & Mean & SD & Mean & SD \\
\hline \multirow[t]{2}{*}{$\beta_{1}^{1}[$ Option 1$]$} & $2.381 *$ & $1.608^{*}$ & $3.881^{*}$ & -0.637 & $2.823 * * *$ & 0.37 & $3.31 * * *$ & 0.412 \\
\hline & $(-2.43)$ & $(-2.44)$ & $(-2.31)$ & $(-0.68)$ & $(-3.36)$ & $(-0.82)$ & $(-3.38)$ & $(-0.3)$ \\
\hline \multirow{2}{*}{$\beta_{1}^{2}[$ Option 2$]$} & 1.421 & 1.782 & 2.338 & 1.751 & $2.223^{* *}$ & -0.701 & $2.530^{* *}$ & 0.353 \\
\hline & $(-1.530)$ & $(-1.66)$ & $(-1.61)$ & $(-1.09)$ & $(-2.83)$ & $(-1.22)$ & $(-2.83)$ & $(-0.65)$ \\
\hline \multirow{2}{*}{$\beta_{2}$ [Groundwater] } & 0.0714 & $-0.164 *$ & 0.0582 & 0.181 & 0.0205 & 0.192 & 0.00307 & 0.11 \\
\hline & $(-0.95)$ & $(-2.24)$ & $(-0.72)$ & $(-1.19)$ & $(-0.35)$ & $(-1.96)$ & $(-0.06)$ & $(-1.34)$ \\
\hline \multirow{2}{*}{$\beta_{3}[$ Aquatic Health $]$} & 0.00003 & 0.00009 & 0.0609 & -0.0086 & $0.0000731^{*}$ & 0.00004 & 0.035 & 0.06 \\
\hline & $(-0.86)$ & $(-1.73)$ & $(-1.68)$ & $(-0.16)$ & $(-2.36)$ & $(-0.88)$ & $(-1.07)$ & $(-1.04)$ \\
\hline \multirow{2}{*}{$\beta_{4}[$ Habitat Loss $]$} & -0.0077 & $-0.021 *$ & -0.0082 & 0.00727 & -0.012 & $0.0239^{*}$ & -0.0083 & $0.0186^{* *}$ \\
\hline & $(-0.87)$ & $(-2.15)$ & $(-1.11)$ & $(-0.57)$ & $(-1.46)$ & $(-2.4)$ & $(-1.38)$ & $(-2.66)$ \\
\hline [Rural & -0.0579 & 0.0856 & -0.0232 & 0.214 & -0.0641 & -0.11 & -0.0489 & 0.0603 \\
\hline Character] & $(-1.15)$ & $(-1.47)$ & $(-0.34)$ & $(-1.42)$ & $(-1.65)$ & $(-1.58)$ & $(-1.22)$ & $(-0.57)$ \\
\hline \multirow{2}{*}{$\beta_{6}[\operatorname{Cos} t]$} & -0.0068 & 0.0211 & -0.0181 & $0.124 *$ & -0.0501 & $0.152 * * *$ & -0.0602 & $0.173^{* *}$ \\
\hline & $(-0.20)$ & $(-0.72)$ & $(-0.45)$ & $(-2.18)$ & $(-1.38)$ & $(-3.83)$ & $(-1.56)$ & $(-3.15)$ \\
\hline \multirow[t]{2}{*}{$\chi^{2}(d f)$} & \multirow{2}{*}{\multicolumn{2}{|c|}{$40.17(7)$}} & 45.02 & & \multirow{2}{*}{\multicolumn{2}{|c|}{$116.6(7)$}} & \multirow{2}{*}{\multicolumn{2}{|c|}{$133.2(7)$}} \\
\hline & & & (7) & & & & & \\
\hline
\end{tabular}

$\mathrm{t}$ statistics in parentheses

$* \mathrm{p}<0.05 \quad * * \mathrm{p}<0.01 \quad * * * \mathrm{p}<0.001$

Hence, from the results demonstrated above, both preference and response heterogeneity relatively decreased but vanished when individuals were allowed to deliberate among their peers. The overall goodness of fit did not differ considerably, and, from the likelihood-ratio test for the joint significance of the SDs, we can reject the null hypothesis that the SDs are equal to zero (See Table 3 that $\operatorname{Prob}>\chi^{2}$ ).

Nonetheless, the DCJ sample result could most likely reflect group (community) values rather than private values for at least two reasons. First, both preference and response heterogeneities were both lower relative to the control and main survey samples. Second, cost is strongly statistically significant in the main survey sample, suggesting that it is one of the essential choice factors. In contrast, cost is a measurably unimportant decision variable in the DCJ sample. This result suggests a decrease in dissent or protest against an increase in the property levy (cost) among DCJ samples, which is in contrast to most non-market valuation outcomes. This result means that it is expected that deliberation helps build consensus by narrowing the differences in views and entertaining a diversity of opinions among the jurors related to the method of financing conservation options.

\subsection{DCJ Policy Implications}

Based on environmental management scenario combinations drawn from the choice experiment and presented as the decision challenges, jurors came up with the best allocation acceptable to all of the jury members. Tables 9 and 10 show the result of this hypothetical DCJ exercise.

This result was achieved by mutual consent from among the levels suggested in each option in the choice set. For example, both groups opted for a moderate increase in the share of total water use from 
Table 9. Scenario 1 allocation: 60 million CAD

\begin{tabular}{lllll}
\hline Attributes & Level Chosen & $\begin{array}{l}\text { Allocation } \\
\text { (million CAD) }\end{array}$ & $\begin{array}{l}\text { Per person payment } \\
\text { per year }\end{array}$ & $\begin{array}{l}\text { Per person payment } \\
\text { over 30 years }\end{array}$ \\
\hline Groundwater & Moderate use $(15 \%)$ & 20 & 8.33 & 250 \\
Aquatic Health & Moderate return $(50000)$ & 0.0 & 0.00 & 0.00 \\
Habitat Loss & Moderate loss $\left(50 \mathrm{KM}^{2}\right)$ & 20 & 8.33 & 250 \\
Rural Character & Density $\left(70 \mathrm{Per} / \mathrm{KM}^{2}\right)$ & 20 & 8.33 & 250 \\
\hline Total & & $\mathbf{6 0}$ & $\mathbf{2 5}$ & $\mathbf{7 5 0}$ \\
\hline
\end{tabular}

Table 10. Scenario 2 Allocation: 120 million CAD

\begin{tabular}{lllll}
\hline Attributes & Level Chosen & $\begin{array}{l}\text { Allocation } \\
\text { (million CAD) }\end{array}$ & $\begin{array}{l}\text { Per person payment } \\
\text { per year }\end{array}$ & $\begin{array}{l}\text { Per person payment } \\
\text { over 30 years }\end{array}$ \\
\hline Groundwater & Moderate use $(15 \%)$ & 40 & 16.67 & 500 \\
Aquatic Health & Moderate return $(50000)$ & 20 & 8.33 & 250 \\
Habitat Loss & Moderate loss $\left(50 \mathrm{KM}^{2}\right)$ & 40 & 16.67 & 500 \\
Rural Character & Density $\left(70 \mathrm{Per} / \mathrm{KM}^{2}\right)$ & 20 & 8.33 & 250 \\
\hline Total & & $\mathbf{1 2 0}$ & $\mathbf{5 0}$ & $\mathbf{1 5 0 0}$ \\
\hline
\end{tabular}

groundwater, a moderate reduction in habitat loss, and about an average population density, and they allocated $\$ 20$ million CAD for each choice. The aquatic habitat was not given priority in this scenario. Groundwater use and habitat loss were given priority in the second scenario, allocating $\$ 40$ million CAD for each over the planning period. In other words, an average person is willing to pay about $\$ 250 \mathrm{CAD}$ over the planning period ( $\$ 8$ CAD per year) for each of the attributes except the aquatic habitat under scenario 1, assuming the population stays constant at 80,000 . Similarly, individuals, on average, are willing to pay about $\$ 500 \mathrm{CAD}$ each for a policy that promotes a decrease in groundwater use and natural habitat loss and \$250 CAD each for a policy that promotes the return of salmon or maintains rural amenities under scenario 2 over the planning period. Alternatively, if all environmental attributes are considered together, an average individual would be willing to pay about $\$ 750 \mathrm{CAD}(\$ 25 /$ year) under scenario 1 and about $\$ 1500 \mathrm{CAD}(\$ 50 /$ year) under scenario 2 for the respective conservation policy alternatives.

This result is expected to conform with the private mean willingness to pay (MWTP) outcome that is calculated based on estimated attributes coefficients and assuming a fixed coefficient on the cost attribute. Formally stated, the MWTP takes the following from (Hole, 2007):

$$
\mathrm{E}\left(\mathrm{WTP}^{j}\right)=E\left(\beta^{j}\right) / \beta^{\text {Levy }}
$$

From Table 11, we see that private MWTP estimates differ a great deal. For instance, the DCJ WTP is about a \$3.1 CAD lower additional charge per property per year on average for an increase in the share of the total water use from groundwater, a $\$ 2.7$ lower additional charge per property per year on average for a decline in the salmon return, a $\$ 0.04$ lower additional charge per year on average for a $\mathrm{km}^{2}$ loss in natural habitat, and a $\$ 4.7 \mathrm{CAD}$ greater additional charge per property per year on average to protect unique rural character. In other words, an average person who participated in the DCJ sample would be willing to pay $10 \%$ and $40 \%$ greater additional charges per property per year on average for a decrease in groundwater use, $50 \%$ and $100 \%$ greater additional charge per property per year on average for aquatic health (salmon fish return), and $36 \%$ less and $95 \%$ greater additional charges per property per year on average to protect the unique rural character relative to the control and main survey samples, respectively. However, the DCJ payments per person are approximately $160 \%$ and $75 \%$ higher average additional charges per property per year for a decrease in groundwater use and for protecting rural character, respectively with an extremely large charge for protecting natural habitat loss. However, the support for this claim is weak, and the data are inconclusive.

The benefit-cost implication is even larger. We showed that heterogeneity decreased after DCJ, and the decrease in the heterogeneity of preferences impacts the WTP, which is used to quantify gains (or losses) of the environmental conservation policy option. Hence, the undiscounted gains or losses (calculated using the DCJ 
payment values for each attribute and for the policy packages if implemented, multiplying them by the average population size of the study region, and assuming the population of the region over the planning period is around 100,000 households) associated with the DCJ sample payment are approximately $130 \%$ higher under scenario 1 and $370 \%$ higher under scenario 2 (see the last four columns of Table 12) than the private values associated with the DCJ treatment sample are.

Table 11. Willingness to pay values after controlling for deliberation effect

\begin{tabular}{llllll}
\hline Sample Group & MWTP & Groundwater & Aquatic Health & Habitat Loss & Rural Character \\
\hline \multirow{3}{*}{ Treatment } & MWTP & -3.11 & -2.71 & -0.04 & 4.76 \\
& Lower 95\% & -9.73 & -11.05 & -0.72 & -8.29 \\
& Upper 95\% & 3.5 & 5.63 & 0.8 & 17.81 \\
\multirow{3}{*}{ Control } & MWTP & -2.82 & -5.93 & -0.93 & 7.49 \\
& Lower 95\% & -14.96 & -35.53 & -4.08 & -27.46 \\
& Upper 95\% & 9.32 & 23.67 & 5.94 & 42.44 \\
\multirow{3}{*}{ Main Survey } & MWTP & 0.07 & 0.00 & -0.6 & 2.43 \\
& Lower 95\% & -2.27 & 0.00 & -0.09 & -0.45 \\
& Upper 95\% & 2.41 & 0.00 & 1.31 & 5.31 \\
\hline
\end{tabular}

Table 11. Benefit-Cost (B-C) Estimates in CAD

\begin{tabular}{|c|c|c|c|c|c|c|c|c|}
\hline \multirow[t]{3}{*}{ Scenario } & \multirow[t]{3}{*}{ Variables } & \multirow[t]{3}{*}{$\begin{array}{l}\text { Private MWTP } \\
\text { After Deliberation }\end{array}$} & \multirow[t]{3}{*}{$\mathrm{CJ}$ payment } & \multirow[t]{3}{*}{$\begin{array}{l}\text { Population } \\
\text { size }\end{array}$} & \multicolumn{2}{|c|}{$\begin{array}{l}\text { Private WTP } \\
(000 \mathrm{~s})\end{array}$} & \multicolumn{2}{|c|}{$\begin{array}{l}\text { CJ payment Based } \\
(000 \mathrm{~s})\end{array}$} \\
\hline & & & & & B-C & $\mathrm{B}-\mathrm{C}$ & B-C & $\mathrm{B}-\mathrm{C}$ \\
\hline & & & & & Per year & 30 years & Per year & 30 years \\
\hline & Ground & 3.11 & 8.33 & 100,000 & 311 & 9,330 & 833 & 24,990 \\
\hline & Water & & & & & & & \\
\hline \multirow[t]{8}{*}{ Scenario 1} & Aquatic & 2.71 & 0 & 100,000 & 271 & 8,130 & 0 & 0 \\
\hline & Habitat & & & & & & & \\
\hline & Natural & 0.04 & 8.33 & 100,000 & 4 & 120 & 833 & 24,990 \\
\hline & Loss & & & & & & & \\
\hline & Rural & 4.76 & 8.33 & 100,000 & 476 & 14,280 & 833 & 24,999 \\
\hline & Character & & & & & & & \\
\hline & Total & 10.62 & 25 & & 1,062 & 31,860 & 2,499 & 74,970 \\
\hline & Benefit & & & & & & & \\
\hline \multirow[t]{10}{*}{ Scenario 2} & Ground & 3.11 & 16.67 & 100,000 & 311 & 9,330 & 1,667 & 50,010 \\
\hline & Water & & & & & & & \\
\hline & Aquatic & 2.71 & 8.33 & 100,000 & 271 & 8,130 & 833 & 24,990 \\
\hline & Habitat & & & & & & & \\
\hline & Natural & 0.04 & 16.67 & 100,000 & 4 & 120 & 1,667 & 50,010 \\
\hline & Loss & & & & & & & \\
\hline & Rural & 4.76 & 8.33 & 100,000 & 476 & 14,280 & 833 & 24,990 \\
\hline & Character & & & & & & & \\
\hline & Total & 10.62 & 50 & & 825 & 31,860 & 5,000 & 150,000 \\
\hline & Benefit & & & & & & & \\
\hline
\end{tabular}


In conclusion, even though the private MWTP values after controlling for the deliberation effect are not comparable to the group (community) WTP values, they capture community values relative to the control and main survey samples. This result is in line with many studies that have compared private stated preference methods for determining MWTP with values based on citizen juries, and it shows that citizen jury values usually produce higher average WTPs by a factor of between two and ten (Macmillan et al., 2002). The most plausible explanation and cautionary note is that deliberation as a group activity forces decisions that are closer to the opinions of those who are more vocal and informed, so the MWTP values could be exaggerated.

\section{Conclusion}

We observed differences in the outcomes of control and treatment samples outcomes to demonstrate the fact that "not only is deliberation about talk, it is about groups" (Mendelberg, 2002). To a certain extent, the result confirms the claim that participatory processes in the form of group deliberations are an improvement over traditional non-market valuation techniques, overcoming the problem of suspending individuals' self-interest in the sense that they are seen as a legitimate mechanisms for policy development and making informed judgments on environmental issues (Christie, Fazey, Cooper, Hyde, \& Kenter, 2012; Howarth \& Wilson, 2006; Niemeyer \& Spash, 2001).

We also observed some congruity between the results using deliberative methods and choice experiments in the sense that integrating methods improves the validity of results obtained from CE and DCJ methods alone. Central to our hypothesis is an empirical investigation of the impact of deliberative juries on community preferences for environmental goods. The result demonstrates that deliberative methods within the CE process enhance the respondents' understanding, their methods for discussing and conceptualizing the goods valued, their thought processes during the transaction, the motivations for their responses, the adequacy of the valuation process used, and the public acceptability of the valuation exercise (Adamowicz et al., 1994; Álvarez-Farizo \& Hanley, 2006; Lienhoop \& Völker, 2016; Powe et al., 2005; Schaafsma, Brouwer, Gilbert, van den Bergh, \& Wagtendonk, 2013; Vargas et al., 2016; Ward, 1999; ?). Hence, deliberation influences individuals' valuation processes in a way that we believe reflects community values more than the traditional $\mathrm{CE}$ valuation method does. Both preference and response heterogeneity essentially decreased when individuals were allowed to deliberate, and the payment values reflect conformity with the group dynamics.

Moreover, jurors' evaluation sheets regarding the content of the jury and the DCJ process also indicate that their knowledge about the environment increased as a result of participating in the DCJ. The majority also viewed the decision-making process as fair and felt that their views were listened to, and they believed that they made well-informed and better choices. In summary, group deliberation markedly affected the kinds of considerations that most mattered to respondents, which consequently affected the choices made and their WTP values.

\section{Acknowledgements}

We are indebted to Dr. Stephan Kroll and Dr. Brett Bruyere for helpful comments. We thank Margaret Bakelaar and other RDCO staff for the support as well as valuable comments and suggestions. This project was conducted with generous support from the Social Sciences and Humanities Research Council (SSHRC), Canada. All errors are our own.

\section{References}

Álvarez-Farizo, B., \& Hanley, N. (2006). Improving the process of valuing non-market benefits: combining citizens juries with choice modelling. Land economics, 82(3), 465-478. https://doi.org/10.3368/le.82.3.465

Álvarez-Farizo, B., Gil, J. M., \& Howard, B. (2009). Impacts from restoration strategies: Assessment through valuation workshops. Ecological Economics, 68(3), 787-797. https://doi.org/10.1016/j.ecolecon.2008.06.012

Adamowicz, W., Louviere, J., \& Williams, M. (1994). Combining revealed and stated preference methods for valuing environmental amenities. Journal of environmental economics and management, 26(3), 271-292. https://doi.org/10.1006/jeem.1994.1017

Ahlheim, M., Ekasingh, B., Fro"r, O., Kitchaicharoen, J., Neef, A., Sangkapitux, C., \& Sinphurmsukskul, N. (2010). Better than their reputation: enhancing the validity of contingent valuation mail survey results through citizen expert groups. Journal of environmental planning and management, 53(2), 163-182. https://doi.org/10.1080/09640560903529196

Aldred, J., \& Jacobs, M. (2000). Citizens and wetlands: evaluating the ely citizens jury. Ecological Economics, 34(2), 217--232. https://doi.org/10.1016/S0921-8009(00)00159-2 
Austin, P. C. (2011). An introduction to propensity score methods for reducing the effects of confounding in

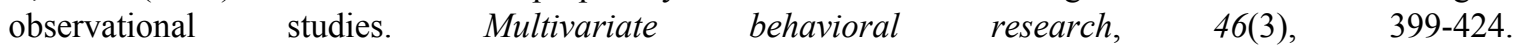
https://doi.org/10.1080/00273171.2011.568786

Blamey, R., Gordon, J., \& Chapman, R. (1999). Choice modelling: assessing the environmental values of water supply options. Australian Journal of Agricultural and Resource Economics, 43(3), 337-357. https://doi.org/10.1111/1467-8489.00083

Brown, T. C., Peterson, G. L., \& Tonn, B. E. (1995). The values jury to aid natural resource decisions. Land Economics, 71(2), 250-260. https://doi.org/10.2307/3146505

Caliendo, M., \& Kopeinig, S. (2008). Some practical guidance for the implementation of propensity score matching. Journal of economic surveys, 22(1), 31-72. https://doi.org/10.1111/j.1467-6419.2007.00527.x

Christie, M., Fazey, I., Cooper, R., Hyde, T., \& Kenter, J. O. (2012). An evaluation of monetary and non-monetary techniques for assessing the importance of biodiversity and ecosystem services to people in countries with developing economies. Ecological economics, 83, 67-78. https://doi.org/10.1016/j.ecolecon.2012.08.012

Coote, A., \& Lenaghan, J. (1997). Citizens' juries: theory into practice. Institute for Public Policy Research.

Cummings, R., Brookshire, D., \& Schulze, W. (1986). Valuing environmental goods: an assessment of the contingent valuation methodrowman and allanheld. Totowa, $N J$.

Dietz, T., Stern, P. C., \& Dan, A. (2009). How deliberation affects stated willingness to pay for mitigation of carbon dioxide emissions: an experiment. Land Economics, 85(2), 329-347. https://doi.org/10.3368/le.85.2.329

Dixon, J., Scura, L., Carpenter, R., \& Sherman, P. (2013). Economic analysis of environmental impacts. Routledge.

Farber, S. C., Costanza, R., \& Wilson, M. A. (2002). Economic and ecological concepts for valuing ecosystem services. Ecological economics, 41(3), 375-392. https://doi.org/10.1016/S0921-8009(02)00088-5

Ferreyra, C., \& Beard, P. (2007). Participatory evaluation of collaborative and integrated water man- agement: insights from the field. Journal of Environmental Planning and Management, 50(2), 271-296. https://doi.org/10.1080/09640560601156532

Greene, W. H. (2012). Econometric analysis, 71e. Stern School of Business, New York University.

Greenland, S., Pearl, J., \& Robins, J. M. (1999). Causal diagrams for epidemiologic research. Epidemiology, 37-48. https://doi.org/10.1097/00001648-199901000-00008

Gregory, R. (2000). Using stakeholder values to make smarter environmental decisions. Environment: science and policy for sustainable development, 42(5), 34-44. https://doi.org/10.1080/00139150009604888

Gregory, R., \& Wellman, K. (2001). Bringing stakeholder values into environmental policy choices: a community-based estuary case study. Ecological Economics, 39(1), 37-52. https://doi.org/10.1016/S0921-8009(01)00214-2

Hole, A. R. (2007). Estimating mixed logit models using maximum simulated likelihood. Stata Journal, 7(3), 388-401.

Howarth, R. B., \& Wilson, M. A. (2006). A theoretical approach to deliberative valuation: aggregation by mutual consent. Land Economics, 82(1), 1-16. https://doi.org/10.3368/le.82.1.1

Jefferson, C. (2016). Citizens juries. Retrieved September 15, 2015, from http://jefferson-center.org/

Kenter, J. O., Hyde, T., Christie, M., \& Fazey, I. (2011). The importance of deliberation in valuing ecosys-tem services in developing countriesevidence from the solomon islands. Global Environmental Change, 21(2), 505-521. https://doi.org/10.1016/j.gloenvcha.2011.01.001

Kontogianni, A., Skourtos, M. S., Langford, I. H., Bateman, I. J., \& Georgiou, S. (2001). Integrating stakeholder analysis in non-market valuation of environmental assets. Ecological Economics, 37(1), 123-138. https://doi.org/10.1016/S0921-8009(00)00270-6

Lechner, M. (2000). A note on the common support problem in applied evaluation studies.

Lienhoop, N., \& MacMillan, D. C. (2007). Contingent valuation: comparing participant performance in group-based approaches and personal interviews. Environmental Values, 209-231. https://doi.org/10.3197/096327107780474500 
Lienhoop, N., \& Vö lker, M. (2016). Preference refinement in deliberative choice experiments for ecosystem service valuation. Land Economics, 92(3), 555-577. https://doi.org/10.3368/le.92.3.555

Macmillan, D. C., Philip, L., Hanley, N., \& Alvarez-Farizo, B. (2002). Valuing the non-market benefits of wild goose conservation: a comparison of interview and group based approaches. Ecological Economics, 43(1), 49-59. https://doi.org/10.1016/S0921-8009(02)00182-9

MacMillan, D., Hanley, N., \& Lienhoop, N. (2006). Contingent valuation: Environmental polling or preference engine? Ecological economics, 60(1), 299-307. https://doi.org/10.1016/j.ecolecon.2005.11.031

Mendelberg, T. (2002). The deliberative citizen: Theory and evidence. Political decision making, deliberation and participation, 6(1), 151-193.

Mitchell, R. C. (2002). On designing constructed markets in valuation surveys. Environmental and Resource Economics, 22(1-2), 297--321. https://doi.org/10.1023/A:1015571100238

Morrison, M., \& Kingsford, R. (2010). The management of inland wetlands and river flows and the importance of economic vaulation in new south wales. Wetlands (Australia), 16(2), 83-98.

Niemeyer, S., \& Spash, C. L. (2001). Environmental valuation analysis, public deliberation, and their pragmatic syntheses: a critical appraisal. Environment and Planning C, 19(4), 567-586. https://doi.org/10.1068/c9s

Payne, J. W., Bettman, J. R., Schkade, D. A., Schwarz, N., \& Gregory, R. (1999). Measuring constructed preferences: Towards a building code. In Elicitation of preferences (pp. 243-275). Springer. https://doi.org/10.1007/978-94-017-1406-8_9

Powe, N., Garrod, G., \& McMahon, P. (2005). Mixing methods within stated preference environmental valuation: choice experiments and post-questionnaire qualitative analysis. Ecological economics, 52(4), 513-526. https://doi.org/10.1016/j.ecolecon.2004.06.022

Revelt, D., \& Train, K. (1998). Mixed logit with repeated choices: households' choices of appliance efficiency level. Review of economics and statistics, 80(4), 647-657. https://doi.org/10.1162/003465398557735

Rosenbaum, P. R., \& Rubin, D. B. (1983). The central role of the propensity score in observational studies for causal effects. Biometrika, 70(1), 41-55. https://doi.org/10.1093/biomet/70.1.41

Rosenbaum, P. R., \& Rubin, D. B. (1984). Reducing bias in observational studies using subclassification on the propensity score. Journal of the American statistical Association, 79(387), 516-524. https://doi.org/10.1080/01621459.1984.10478078

Sagoff, M. (1988). The economy of the earth: Philosophy, law, and the environment. Cambridge University Press.

Sagoff, M. (1998). Aggregation and deliberation in valuing environmental public goods:: A look beyond contingent pricing. Ecological Economics, 24(2), 213-230. https://doi.org/10.1016/S0921-8009(97)00144-4

Schaafsma, M., Brouwer, R., Gilbert, A., van den Bergh, J., \& Wagtendonk, A. (2013). Estimation of distance-decay functions to account for substitution and spatial heterogeneity in stated preference research. Land Economics, 89(3),514-537. https://doi.org/10.3368/le.89.3.514

Schkade, D. A., \& Payne, J. W. (1994). How people respond to contingent valuation questions: a verbal protocol analysis of willingness to pay for an environmental regulation. Journal of Environmental Economics and Management, 26(1), 88-109. https://doi.org/10.1006/jeem.1994.1006

Schuman, H. (1996). The sensitivity of cv outcomes to cv survey methods. Edward Elgar Brookfield, VT.

Spash, C. L., \& Hanley, N. (1995). Preferences, information and biodiversity preservation. Ecological economics, 12(3), 191-208. https://doi.org/10.1016/0921-8009(94)00056-2

StataCorp, L., et al. (2013). teffects psmatch propensity-score matching. Special Edition Release, 13.

Street, J., Duszynski, K., Krawczyk, S., \& Braunack-Mayer, A. (2014). The use of citizens' juries in health policy decision-making: a systematic review. Social Science \& Medicine, 109, 1-9. https://doi.org/10.1016/j.socscimed.2014.03.005

Vargas, A., Lo, A. Y., Rohde, N., \& Howes, M. (2016). Background inequality and differential participation in deliberative valuation: Lessons from small-group discussions on forest conservation in colombia. Ecological Economics, 129,104-111. https://doi.org/10.1016/j.ecolecon.2016.06.009

Ward, H. (1999). Citizens' juries and valuing the environment: A proposal. Environmental Politics, 8(2), 75-96. 
https://doi.org/10.1080/09644019908414462

\section{Copyrights}

Copyright for this article is retained by the author(s), with first publication rights granted to the journal.

This is an open-access article distributed under the terms and conditions of the Creative Commons Attribution license (http://creativecommons.org/licenses/by/4.0/). 